\title{
O uso de mapas conceituais na identificação de obstáculos à aprendizagem de um tema que gera conflito entre ciência e crença: a origem da vida
}

\author{
Núbia Costa Nascimento ${ }^{1}$ \\ Rosiléia Oliveira de Almeida ${ }^{2}$ \\ Fábio Luís Alves Pena ${ }^{3}$
}

\begin{abstract}
RESUMO
Ensinar ciências envolve obstáculos, sendo que, quando o tema suscita conflitos, o desafio é ainda maior. Esta pesquisa objetivou identificar quais são os principais obstáculos no aprendizado de um tema que gera conflito entre ciência e religião: a origem da vida. Os participantes da pesquisa foram 141 estudantes do IFBA de Simões Filho, que cursavam o $3^{\circ}$ ano do Ensino Médio. Os alunos elaboraram dois mapas conceituais, que foram analisados qualitativamente. Foram identificados seis obstáculos: 1 - diferença entre a bagagem de conhecimento científico e religioso, 2 - divulgação de informações científicas erradas em meios de comunicação, 3 - confusões sobre o significado de teoria e lei, 4 conhecimentos prévios equivocados, 5 - rejeição das teorias científicas por razões religiosas e 6 - postura cientificista de professores durante as aulas. O conhecimento científico pode contribuir para um pensar crítico, mas é essencial respeitar a diversidade sociocultural, como também seus contextos de aplicação, para assim se construir uma sociedade cada vez mais igualitária e justa.
\end{abstract}

PALAVRAS-CHAVE: Ciência, religião, mapa conceitual, aprendizagem, origem da vida.

\footnotetext{
1 Doutora. Instituto Federal de Educação, Ciência e Tecnologia da Bahia, Simões Filho, Bahia, Brasil. https://orcid.org/0000-0002-6729-8134. nbacosta@ifba.edu.br.

2 Doutora. Universidade Federal da Bahia, Salvador, Bahia, Brasil. https://orcid.org/0000-0002-6804-1816. rosileiaoalmeida@ufba.br.

3 Doutor. Instituto Federal de Educação, Ciência e Tecnologia da Bahia, Simões Filho, Bahia, Brasil. https://orcid.org/0000-0002-9274-1687.fabiopena@ifba.edu.br.
} 
The use of conceptual maps in the identification of obstacles to the learning of a subject that generates conflict between science and belief: the origin of life

\begin{abstract}
Teaching science involves obstacles, and when the subject raises conflicts, the challenge is even greater. This research aimed to identify which are the main obstacles in the learning of a subject that generates conflict between science and religion: the origin of the life. The participants in this study were 141 students of 3rd year of High Scholl from IFBA of Simões Filho. The students elaborated two conceptual maps, that were analyzed using a qualitative approach. Six obstacles have been identified: 1. difference between scientific and religious background knowledge, 2. dissemination of erroneous scientific information in the media, 3. confusions on the meaning of theory and law, 4. mistaken previous knowledge, 5. rejection of scientific theories due to religious reasons and 6. scientistic posture of teachers during classes. The scientific knowledge can contribute to a critical thinking, but it is essential to respect the socio-cultural diversity, as well as their application contexts, only then we will build an ever more equal and just society.
\end{abstract}

KEYWORDS: Science, religion, conceitual map, learning, origin of life.

$$
* * *
$$

\title{
Introdução
}

A ciência, uma das formas de saber, surgiu a partir da necessidade de se compreender mais profundamente o mundo, bem como trocar informações precisas levando à elaboração de sistemas mais estruturados de organização do conhecimento (ARAÚJO, 2006, p. 131). Busca produzir explicações sobre os fenômenos e tem como objeto de estudo o mundo natural (MOTA, 2013, p. 95), o desenvolvimento tecnológico, próprio do ser humano, além das relações sociais. 
Ensinar sobre os conhecimentos científicos engloba uma série de obstáculos, sendo que, quando o tema envolve conflitos entre ciência e crença, o desafio é bem maior. A religião e a ciência fornecem compreensões diferentes sobre o mundo natural. Nas diferentes fases da história, ambas protagonizaram avenças e desavenças e, assim, a relação entre essas duas visões de mundo sempre foi complexa, geralmente retratada com base em conflitos (MOTA, 2013, p. 101).

Sabe-se que as crenças religiosas são pautadas por estruturadas visões de mundo. Quando essas visões estabelecem contrastes com o que é transmitido nas salas de aula podem ocorrer interferências e até mesmo impedimentos à consideração da plausibilidade do que se ensina, inclusive no que se refere às hipóteses científicas (PORTO; FALCÃO, 2010, p. 14). Diante de tal situação, esta pesquisa teve o objetivo de identificar quais foram os principais obstáculos ao aprendizado de um conhecimento que gera conflito entre ciência e religião, a origem da vida, sendo que para isso foram utilizados mapas conceituais.

O mapa conceitual é um instrumento inspirado na Teoria da Aprendizagem Significativa de David Ausubel. $\mathrm{Na}$ aprendizagem significativa há uma interação entre o novo conhecimento e o já existente, na qual ambos se modificam. Na medida em que o conhecimento prévio serve de base para a atribuição de significados à nova informação, ele também se modifica, ou seja, os subsunçores, conhecimentos anteriores presentes na estrutura cognitiva do indivíduo, vão adquirindo novos significados, se tornando mais diferenciados, mais estáveis (AUSUBEL, 1968, p. 37-38; 2000, p. 69; MOREIRA, 1997, p. 1; 2012, p. 2).

O mapa conceitual, técnica desenvolvida por Joseph Novak e colaboradores, caracteriza-se pela apresentação de conceitos de forma hierárquica em que conceitos mais gerais e inclusivos são dispostos no topo do mapa, decrescendo no grau de generalidade e inclusividade até chegar aos exemplos, na base do mapa (ALMEIDA; FONTANINI, 2010, p. 407). 
O que o aluno elabora é o seu mapa conceitual pessoal e o importante não é se está certo ou errado, mas se ele proporciona evidências de que o aluno está aprendendo significativamente o conteúdo (MOREIRA, 1997, p. 11). Essa foi a razão para a escolha do mapa conceitual, por ser um instrumento flexível que possibilita que o estudante utilize o conhecimento adquirido em aula (científico) e de outras fontes (religioso e cotidiano).

Compreender como os estudantes relacionam conceitos é um importante passo para planejar futuras intervenções, rever os procedimentos e, principalmente, conhecer peculiaridades do aprendizado pelos discentes.

\section{Procedimentos metodológicos}

Participaram desta pesquisa 141 estudantes do Instituto Federal da Bahia (IFBA), campus Simões Filho, que cursavam, em 2015, o $3^{\circ}$ ano do Ensino Médio Técnico, no qual o conhecimento científico sobre a origem da vida foi ministrado. Os estudantes foram classificados como pertencentes a um dos seguintes grupos: Ateus - não acreditam em Deus, outra entidade divina ou ser espiritual; Ex-religiosos - já tiveram uma religião e acreditam em Deus ou em uma força espiritual superior, mas atualmente não estão ligados a uma instituição religiosa; Católicos - pertencem à religião Católica; Protestantes - pertencem a uma religião que rompeu com os dogmas da igreja Católica e utilizam a Bíblia, o Velho ou o Novo Testamento como base para seus ensinamentos e conduta moral; Espíritas e Espiritualistas - acreditam na existência de seres espirituais e na reencarnação, frequentando ou não um templo ou centro espírita; e Adeptos de Religiões Afrobrasileiras - acreditam na existência dos orixás ou divindades da natureza e praticam rituais relacionados a essa crença. Não houve um número suficiente de estudantes classificados em religiões orientais como o islamismo, hinduísmo ou budismo (apenas um) e indígenas 
(nenhum) para participar desta pesquisa, razão pela qual não foram adotadas essas categorias.

Inicialmente, para que os estudantes se apropriassem da técnica de elaboração, eles desenvolveram mapas conceituais com o tema ecologia, evolução e biologia. No final da unidade, quando as aulas sobre biogênese $\mathrm{x}$ abiogênese, Teoria da Panspermia, Teoria da Evolução Química, formação e características da Terra primitiva e aparecimento dos primeiros seres vivos foram desenvolvidas, foi solicitado que os estudantes elaborassem outro mapa conceitual com o tema "origem da vida", este com o objetivo de identificar o conhecimento apreendido, sendo que deveria conter de 10 a 15 conceitos.

Quatro meses depois, sem que fosse previamente informado, foi solicitado que os estudantes elaborassem outro mapa conceitual sobre "origem da vida", com as mesmas características do anterior, com a finalidade de identificar o conhecimento científico retido e como este estava se relacionando com os conhecimentos anteriores (religiosos e do cotidiano).

Nos dois momentos os estudantes não consultaram nenhum material, sendo que poderiam utilizar todo conhecimento que possuíam, não apenas o científico ensinado em sala de aula. Os mapas foram analisados qualitativamente e, quando necessário, foram realizadas entrevistas sobre os mapas para esclarecer algumas informações apresentadas. Além dos mapas conceituais e entrevistas, também foram pesquisados artigos científicos com a finalidade de identificar, na literatura, barreiras relacionadas ao aprendizado de conhecimentos que apresentam conflito entre ciência e religião, visando subsidiar a análise.

\section{Resultados e discussões}

Analisando e comparando o primeiro com o segundo mapa conceitual de cada estudante, foram facilmente observados indícios da aprendizagem. No primeiro mapa, a maioria dos estudantes, além de terem empregado os 
principais conceitos relacionados ao tema origem da vida, como: abiogênese, biogênese, panspermia e evolução química, também citaram nomes de cientistas: Redi, Spallazanni, Pauster, Aristóteles, Needhan, Oparin, Haldane, Miller, Urey etc., e de experimentos relacionados: "Experimento com pedaços de carne", "caldo orgânico", "pescoço de cisne" e "experimento de Miller", como exemplificado na Figura 1. Os conceitos mais abrangentes foram, primeiramente, citados próximo ao topo do mapa e os mais específicos foram citados na parte média e inferior, representação que traduziu a organização mental dos conceitos pelos estudantes, conforme orientação prévia.

FIGURA 1. Mapa conceitual inicial do estudante A.

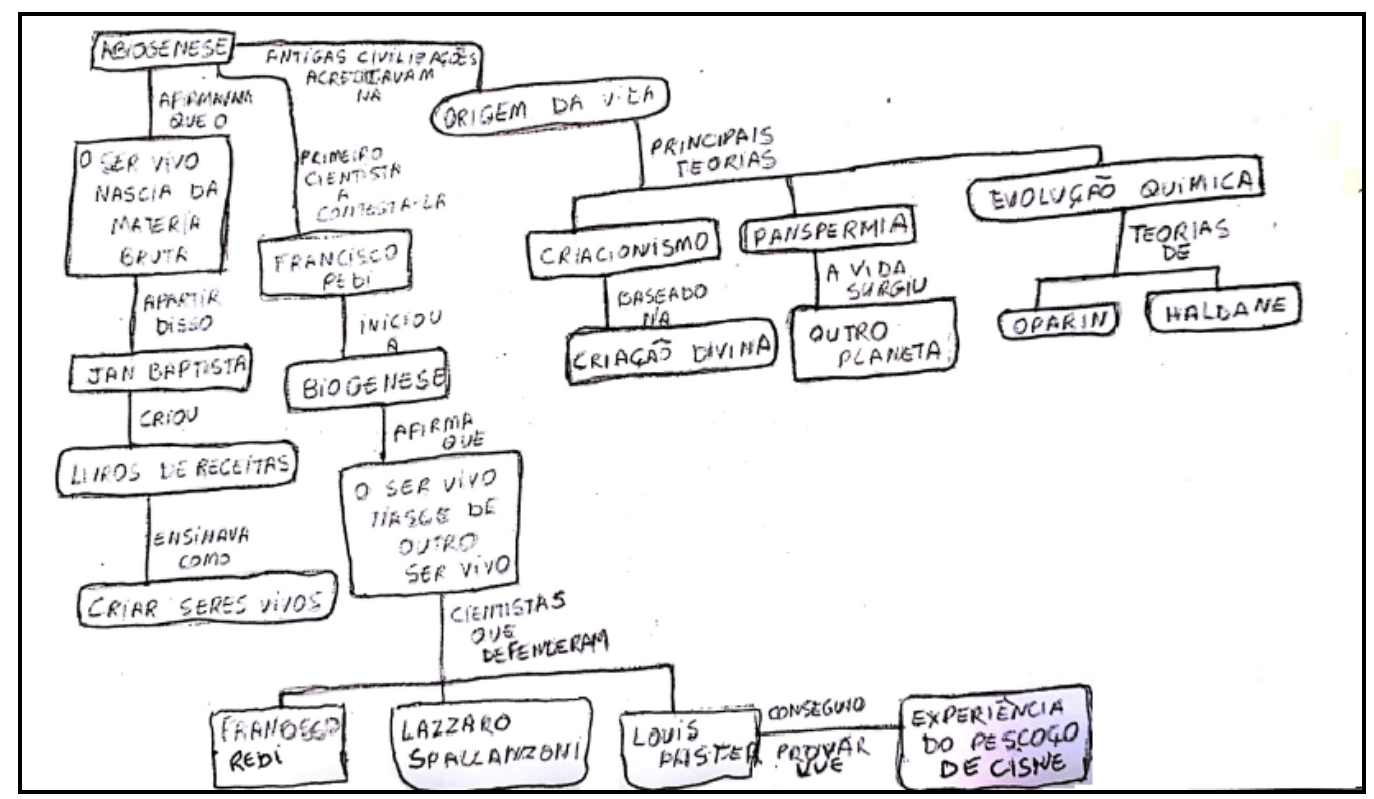

Fonte: Pesquisa realizada pelos autores, 2015.

No segundo mapa, elaborado quatro meses após a solicitação do primeiro, sem um aviso prévio, para que os estudantes não tivessem a oportunidade de revisar o assunto, foi possível a visualização da interação do conhecimento prévio, religioso e do cotidiano, por exemplo, e o adquirido, o conhecimento científico relacionado ao tema origem da vida. Nesse segundo mapa conceitual os nomes dos cientistas e experimentos não foram 
citados pela maioria dos estudantes, pois necessitariam de outros estímulos para serem relembrados (Figura 2). Tal representação é explicada pela teoria de Ausubel, que contempla uma justificativa para o esquecimento mais fácil de informações isoladas, enquanto aquelas que se relacionam de forma substantiva aos conceitos mais gerais, por apresentarem relações com muitos outros conceitos, estão mais disponíveis na estrutura cognitiva, ou seja, conceitos relacionados diretamente aos subsunçores são mais estáveis e, por isso, mais facilmente mobilizados.

FIGURA 2. Segundo mapa conceitual do estudante A.

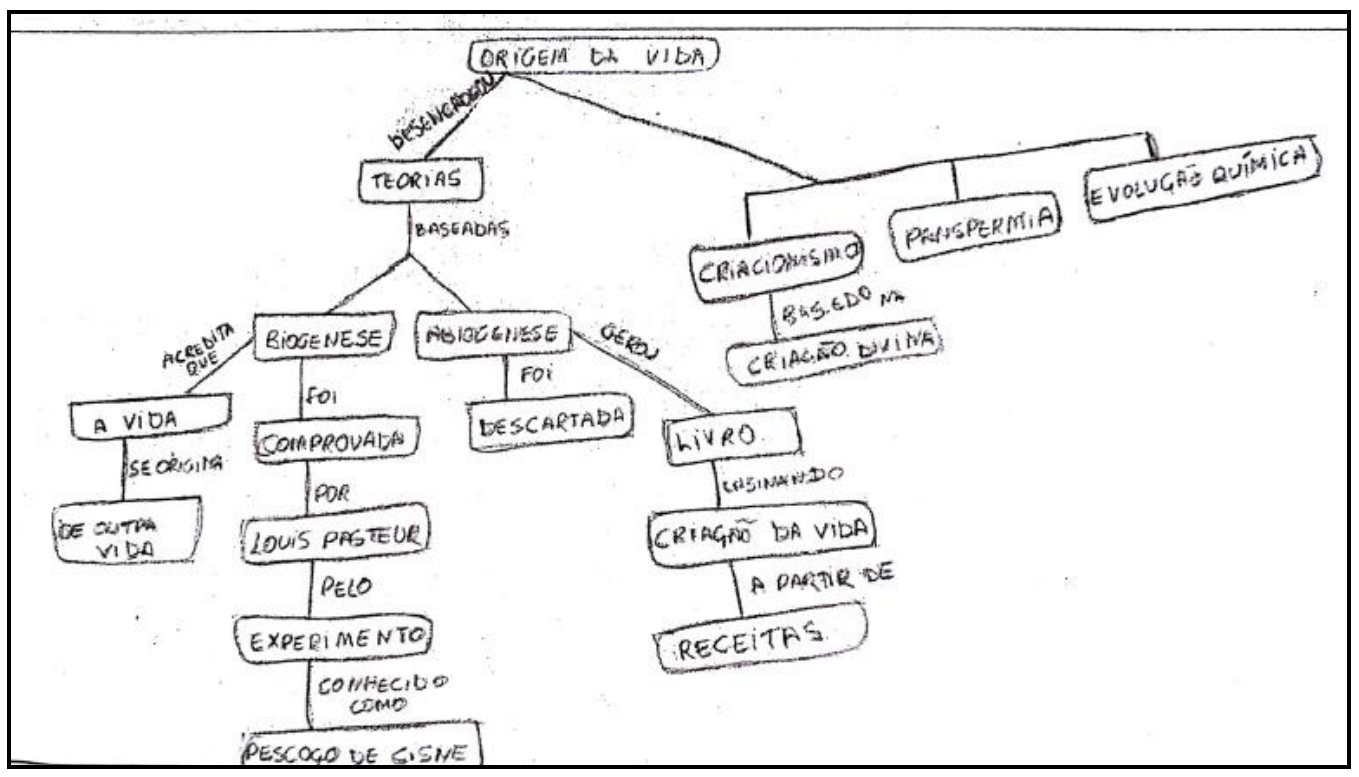

Fonte: Pesquisa realizada pelos autores, 2015.

Comparando a primeira versão e a segunda versão dos mapas conceituais por grupo religioso, dos 16 estudantes Ateus, 04 estudantes citaram o criacionismo nos mapas inicial e final (Figura 1 e 2), 03 citaram apenas no mapa inicial, 02 citaram apenas no mapa final e 07 não citaram o criacionismo. No entanto, diferente de outros grupos, o criacionismo foi citado sem referência às informações bíblicas. Quanto à utilização de conceitos religiosos por parte dos Ateus, é importante esclarecer que ter um conhecimento não significa acreditar nele, portanto a postura dos Ateus em citar o criacionismo é compreensível. Dos 31 estudantes Ex-religiosos, 17 
citaram o criacionismo no primeiro e no segundo mapas, 03 estudantes citaram apenas no primeiro, 06 apenas no segundo, e 05 não fizeram nenhuma alusão a algum conhecimento religioso.

Dos 32 estudantes Católicos, 21 citaram o criacionismo nos mapas inicial e final, 04 citaram no primeiro, 07 no segundo e nenhum aluno deixou de citar em algum momento. Entre os 50 alunos Protestantes, 27 citaram o criacionismo no primeiro e segundo mapas, 03 citaram apenas no primeiro, 08 no segundo mapa e 12 estudantes não citaram (Tabela 1). $\mathrm{O}$ que chama atenção nesses dois grupos é que muitos estudantes ligaram o conceito "criacionismo" a palavras como: Bíblia, Deus, 7 dias, gênesis, dentre outros, como pode ser observado no mapa do estudante B, protestante (Figura 3).

FIGURA 3 - Segundo mapa conceitual do estudante B.

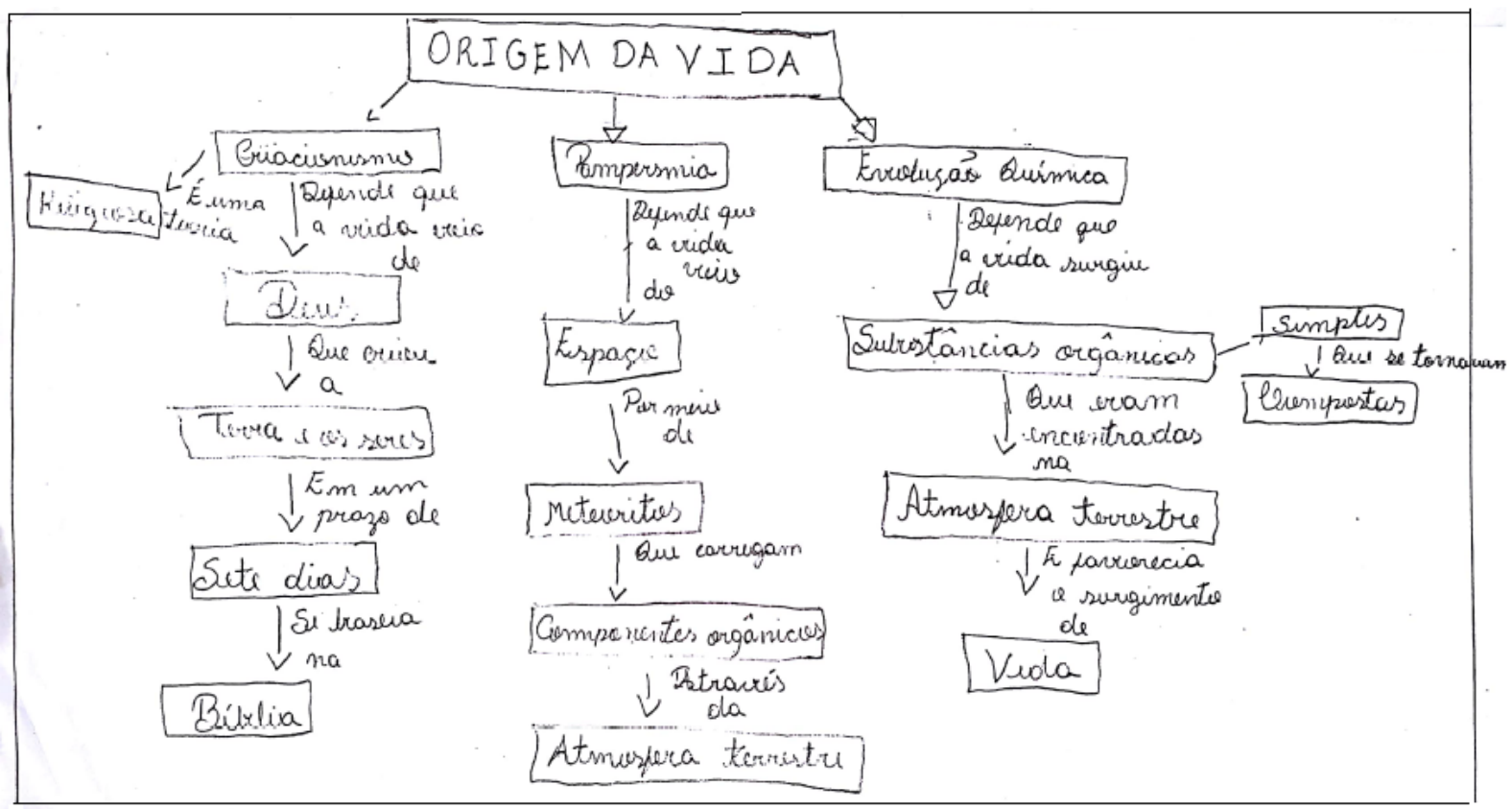

Fonte: Pesquisa realizada pelos autores, 2015.

Entre os 07 estudantes Espíritas, 02 citaram o criacionismo no primeiro e segundo mapas, 01 aluno no primeiro mapa e 04 apenas no segundo mapa. Quanto aos 05 estudantes Adeptos de religiões 
afrodescendentes, apenas 01 aluno citou criacionismo nos dois mapas, 03 citaram no primeiro mapa e 01 apenas no segundo mapa (Tabela 1).

Independentemente da crença, o criacionismo foi citado por 117 estudantes, no primeiro e/ou no segundo mapa, enquanto 24 alunos não o citaram em nenhum momento. Esse resultado mostra o quanto o conhecimento religioso está presente na vida dos estudantes brasileiros, seja pela convivência familiar, meios de comunicação, redes sociais ou influência histórico-cultural (Tabela 1).

TABELA 1 - Citação de ideias criacionistas na primeira e na segunda versão dos mapas conceituais.

\begin{tabular}{l|c|c|c|c|c}
\hline \multicolumn{1}{c|}{ Crença } & $\begin{array}{c}\text { Total de } \\
\text { alunos }\end{array}$ & $\begin{array}{c}\text { Apenas no } \\
\text { primeiro } \\
\text { mapa }\end{array}$ & $\begin{array}{c}\text { Apenas no } \\
\text { segundo } \\
\text { mapa }\end{array}$ & $\begin{array}{c}\text { No } \\
\text { primeiro e } \\
\text { no segundo } \\
\text { mapas }\end{array}$ & $\begin{array}{c}\text { Em } \\
\text { nenhum } \\
\text { dos mapas }\end{array}$ \\
\hline Ateus & 16 & 03 & 02 & 04 & 07 \\
\hline Ex-religiosos & 31 & 03 & 06 & 17 & 05 \\
\hline Católicos & 32 & 04 & 07 & 21 & 0 \\
\hline Protestantes & 50 & 03 & 08 & 27 & 02 \\
\hline Espíritas espiritualistas & 07 & 01 & 04 & 02 & 0 \\
\hline Adeptos RAB & 05 & 03 & 01 & 01 & 0 \\
\hline Total & 141 & 17 & 28 & 72 & 24 \\
\cline { 2 - 5 }
\end{tabular}

Fonte: Pesquisa realizada pelos autores, 2015.

O primeiro obstáculo observado no aprendizado de um conhecimento que gera conflito entre ciência e religião foi a diferença entre os níveis de conhecimento científico e religioso entre os jovens brasileiros. Enquanto a maioria dos alunos desconhece teorias científicas sobre a origem da vida, até mesmo estudantes com pouca ligação religiosa manifestaram algum saber sobre a versão religiosa da origem da vida, como os Ateus, em que, dos 16 estudantes, 09 citaram ideias criacionistas; e os Ex-religiosos em que, dos 31 estudantes, 26 também citaram o criacionismo. 
Foi verificado, na atual pesquisa, que um número maior de estudantes citou o criacionismo no segundo mapa, 100 alunos, do que no primeiro, 89 alunos. Outro ponto observado é que os estudantes detalharam mais informações sobre o criacionismo no segundo mapa, quando já haviam esquecido algumas informações científicas, do que no primeiro, como por exemplo o estudante protestante B (Figura 3).

Em 2013 foi publicada uma pesquisa que comparou o nível de conhecimento científico de alunos no Brasil e na Itália, a qual revelou um cenário preocupante no nosso país no que se refere ao ensino das teorias científicas. O estudo indicou que a precária formação científica dos estudantes de ensino médio do Brasil os leva a recorrer a sua bagagem cultural e religiosa para explicar a evolução dos seres vivos e a origem da espécie humana, algo que não se observa entre os italianos, que recebem uma educação científica mais sólida (MARQUES, 2015, f, 1).

Em concordância com Marques (2015, f. 1), podemos dizer que, na ausência de informações científicas para explicar um determinado fenômeno, muitas pessoas apresentam respostas relacionadas ao conhecimento cotidiano, religioso ou sobrenatural. Tal comportamento indica que os subsunçores relacionados aos conhecimentos religiosos são mais estáveis que os científicos, assim, caso estes não sejam consistente e continuamente estimulados, podem ser facilmente esquecidos.

$\mathrm{O}$ segundo obstáculo observado está relacionado à maneira como o conhecimento é construído nos ambientes não-formais de ensino como, por exemplo, em séries, filmes e documentários. Determinadas obras confundem os estudantes, como o caso da teoria evolutiva, que é muitas vezes representada de forma lamarckista, e a ideia de que humanos e dinossauros viveram no mesmo período (OLIVEIRA, 2015, p. 169). No caso da origem da vida, uma ideia muito difundida em filmes e documentários é a de que a vida foi iniciada na Terra por seres alienígenas com uma estrutura orgânica complexa e com uma inteligência superior, como foi observado em documentários de uma série chamada "Alienígenas do Passado" da History. 
Durante o presente estudo, no primeiro mapa conceitual o aluno C escreveu o que pode ser observado na Figura 4.

Figura 4 - Ligações conceituais escrito pelo aluno C no primeiro mapa conceitual.

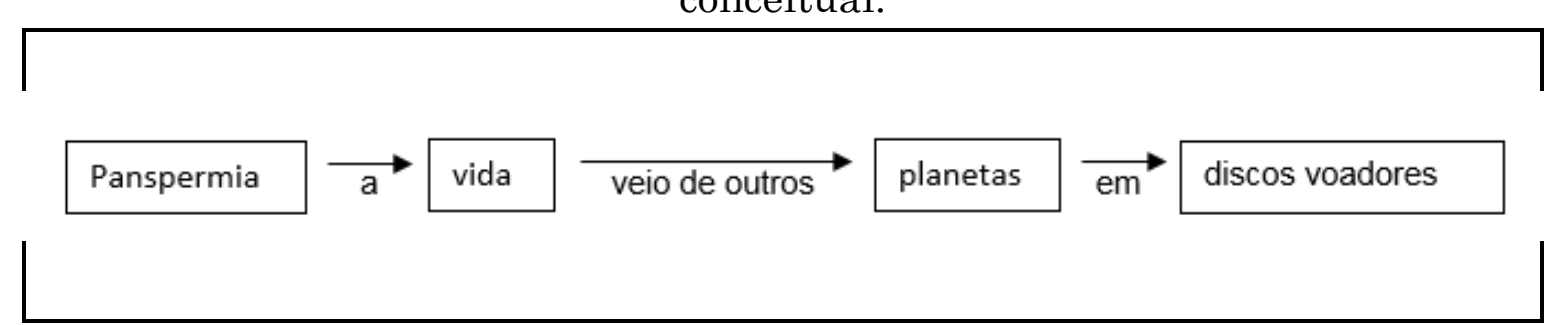

Fonte: Pesquisa realizada pelos autores, 2015.

Como tal informação não foi citada em aula, o estudante foi questionado durante a entrevista sobre como obteve tal conhecimento, sendo que ele respondeu que tinha assistido a um filme que declarava que os habitantes de Marte haviam trazido formas de vida para a Terra. Mesmo sendo um filme de ficção, o estudante não soube demarcar diferenças entre uma situação plausível e a imaginação, o que dizer então de crianças que assistem animações infantis que mostram dinossauros e mamíferos, como primatas, mamutes, tigres-dentes-de-sabre e bichos-preguiça, convivendo em um mesmo período?

O terceiro obstáculo notado mostra a dificuldade que alunos demonstrar ter sobre a diferença entre teoria e lei. Neste estudo foi observado que a palavra teoria foi utilizada de forma generalizada e associada a diversos conhecimentos, como teoria da biogênese, teoria da abiogênese, teoria criacionista, teoria da panspermia, teoria da evolução química. Ao serem questionados na entrevista sobre o motivo de terem usado a palavra teoria para tais conhecimentos, os estudantes declararam que estes conhecimentos ainda precisavam ser comprovados, confundindo o significado de teoria com hipótese e esquecendo que algumas dessas ideias foram refutadas, como é o caso da abiogênese, ou não são científicas por não poderem ser verificadas, como é o caso do criacionismo. Ao serem questionados sobre um conhecimento científico comprovado empiricamente 
deram como exemplo as Leis de Mendel, a Lei da Gravidade, a Lei da Inércia, entre outras. Muitos estudantes não dão uma plena credibilidade às teorias da origem da vida e da evolução por não saberem o significado científico das palavras teoria e lei.

Os estudantes definem teoria como uma hipótese que depende de testes sucessivos, enquanto lei, ao contrário, é um fato comprovado por vários testes aplicados. (ALTERS, 2004, p. 20). Ou seja, na visão discente teoria seria um conhecimento que ainda está sendo testado e, por isso, pode ser derrubado, enquanto lei seria um conhecimento provado e consolidado. Essa interpretação é equivocada, segundo Maruyama, Braga e Guerra (2011, p. 3), pois "as leis estão num nível diferente das teorias por terem uma amplitude menor. [...] Teorias articulam leis num sistema mais amplo. Apesar de ambas serem construções, as leis apresentam um caráter menor de mutabilidade".

A teoria tem um caráter explicativo mais universal do que a lei científica, abrangendo um espectro mais amplo, possuindo a característica de estruturar as uniformidades e regularidades explicadas pelas leis científicas. Teorias não atingem o total de aspectos que envolvem fenômenos da realidade, mas relacionam aspectos diversos e que não são diretamente observáveis (MORESI, 2003, p. 8). Leis científicas apresentam um grau maior de confirmação empírica e, consequentemente, apresentam maior confiabilidade, no entanto, estão inseridas no todo funcional de uma teoria.

A confusão que estudantes e professores costumam fazer com relação aos conceitos de teoria e lei faz com que a teoria da evolução, a teoria da evolução química e a teoria da panspermia sejam consideradas frágeis, já que, na visão deles, lei é comumente um conhecimento forte e teoria algo que não está totalmente explicado. Tal situação revela que é essencial que o professor esclareça o significado das palavras teoria, lei e hipótese ao trabalhar temas como evolução ou origem da vida.

Uma das funções do espaço escolar é aproximar a Ciência e a Tecnologia da sociedade, criando uma linguagem acessível aos estudantes, 
por meios inovadores que estimulem a curiosidade e motivem os jovens para discutir as implicações sociais da Ciência, além de aprofundarem seus conhecimentos sobre o tema. Esse é um passo importante para uma adequada alfabetização científica que, de acordo com Oliveira (2015, p. 18), é a familiaridade desejada por parte do público em geral com a ciência.

O quarto obstáculo observado está relacionado aos conhecimentos equivocados. Foi observado neste estudo que muitos alunos utilizaram, no segundo mapa conceitual, a Teoria do Big Bang para explicar a origem da vida. Dos 141 estudantes que participaram da pesquisa 16, mesmo depois de terem estudado sobre as explicações científicas atualmente aceitas, continuaram sem discernimento sobre as informações relativas a origem do universo e origem da vida. Como os exemplos citados nas Figuras 5 e 6.

Figura 5 - Ligações conceituais equivocadas do estudante D observada no segundo mapa conceitual.

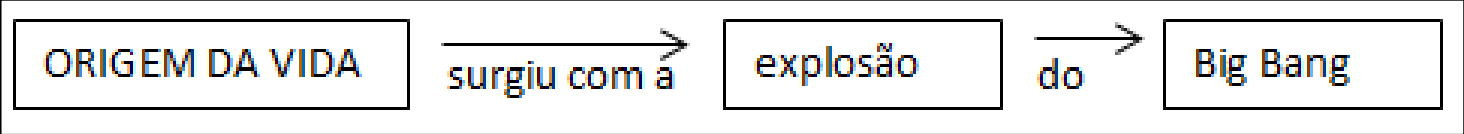

Fonte: Pesquisa realizada pelos autores, 2015.

Figura 6 - Ligações conceituais equivocadas do estudante E observada no segundo mapa conceitual.

\begin{tabular}{|l|l|l|l|l|l|l|}
\hline ORIGEM DA VIDA é explicada pela & $\begin{array}{l}\text { Teoria da } \\
\text { evolução }\end{array}$ & de
\end{tabular}

Fonte: Pesquisa realizada pelos autores, 2015.

Numa investigação realizada por Hanley, Bennett e Ratcliffe (2014, p. 1210-1229) com jovens ingleses do ensino básico adeptos do Cristianismo, Islamismo e sem religião, para verificar se a formação religiosa influenciava as opiniões e atitudes em relação à origem do universo e da vida, foi constatado que os estudantes não distinguem claramente a origem da vida e 
a origem do universo, o que reforça as observações de pesquisadores quanto à dificuldade de mudar conhecimentos prévios considerados equivocados.

Mello (2008, p. 60) realizou uma investigação com alunos do $3^{\circ}$ ano do ensino médio sobre as concepções dos fenômenos que regem a vida relacionados à Biologia, constatando que a origem do universo é associada à origem da vida, ou seja, existe uma confusão por parte dos estudantes entre o surgimento do cosmos e o aparecimento das primeiras formas de vida. De acordo com a referida autora, esse equívoco pode estar relacionado, dentre outros fatores, com a falta de uma visão mais clara sobre o tempo e espaço.

O quinto obstáculo observado foi a rejeição das teorias científicas por razões religiosas. Ao serem questionados na entrevista se acreditavam nas informações científicas, muitos estudantes do grupo dos Protestantes e alguns Católicos declararam que acreditavam apenas nas explicações bíblicas. Alunos dos outros grupos declararam que acreditavam em Deus, acreditavam na explicação científica sobre origem da vida por evolução química, não acreditavam na teoria da panspermia, e não acreditavam que a Terra tinha sido criada em seis dias, ou seja, acreditavam e duvidavam em alguns pontos tanto do conhecimento científico quanto do conhecimento religioso.

Segundo Oliveira (2015, p. 7), que fez um estudo sobre os aspectos socioculturais que influenciam a aceitação/rejeição das teorias evolutivas, "as visões de mundo dos estudantes, oriundas de suas interações sociais e culturais, podem influenciar a aprendizagem, as atitudes e os valores atribuídos à ciência”. Nesse estudo, Oliveira obteve indícios de que a rejeição seria influenciada pela religião, pois os estudantes evangélicos apresentaram níveis mais baixos de concordância com relação à teoria evolutiva.

É importante ressaltar que o aprendizado e a crença em um tema são eventos distintos que podem conviver em um mesmo indivíduo a depender de sua postura (OLIVEIRA, 2009, p. 30). No entanto, como observado em outros estudos, sempre que a visão científica e religiosa entram em conflito 
muitas pessoas acreditam que devem se posicionar defendendo um conhecimento e abandonando ou negando o outro (TRIGO, 2005; MILLER; SCOTT; OKAMOTO, 2006; OLIVEIRA, 2009; 2015; NASCIMENTO, 2017).

Essa situação leva a um sexto obstáculo ao aprendizado dos conhecimentos científicos que geram conflito entre ciência e crença: a postura do professor.

Durante a entrevista foi perguntado como os professores de Sociologia, História, Geografia, Física e Biologia abordavam temas relacionados a religião e ciência, como origem do universo, origem da vida, eras geológicas e evolução biológica e humana. Os estudantes declararam que ficavam indignados com os professores que menosprezavam suas crenças religiosas e complementaram afirmando que as aulas eram mais agradáveis quando o professor não apresentava esse tipo de postura. Ao serem questionados como reagiam perante tais professores, um deles respondeu: "eu costumo partir para o debate", outro disse: "prefiro não falar, tem professores que ficam dizendo indiretas mesmo depois", um outro declarou: "eu prefiro ficar quieto, mesmo que eu fale o que penso o professor não mudará de opinião mesmo!”.

Um estudo feito por Silva et al. (2013, p. 2-15) reproduziu, com estudantes brasileiros de diversos níveis escolares, uma pesquisa realizada com estudantes da Inglaterra que utilizou assertivas com um posicionamento radical, como por exemplo sobre "O evolucionismo ateísta, que defende que a evolução torna desnecessário e absurdo acreditar em Deus. Silva et al. (2013, p. 1) observaram que, provocados por assertivas que negam a religiosidade frente à evolução biológica, os brasileiros mostraramse mais irredutíveis e sustentaram uma percepção mais dogmática do que os britânicos. Esta postura indica que, em um confronto radical entre o conhecimento científico sobre a origem e a evolução da vida e o conhecimento religioso, os estudantes brasileiros têm uma forte tendência a optar pela religião, sugerindo a necessidade de cuidado ao trabalhar tais temas na sala de aula. 
No atual estudo foi observado, durante as entrevistas, que quando o conhecimento da teoria científica e a visão religiosa entram em conflito, os entrevistados reagem de forma a se posicionar defendendo o conhecimento religioso e abandonando ou negando o conhecimento científico. Diante disso, é importante fazer uma demarcação epistemológica entre conhecimento científico e religioso antes de iniciar temas como origem da vida ou evolução, deixando claro que o objetivo da aula é apresentar o conhecimento científico e não mudar crenças. As óticas da ciência e da religião sobre a origem da vida devem ser compreendidas como conhecimentos diferentes em que não há necessidade que ocorra a escolha de um em detrimento do outro. (NASCIMENTO, 2017, p. 134).

Por conta disso, no ensino de ciências não deve haver tentativa de que os estudantes abandonem as suas visões de mundo para que acreditem nas teorias e nos conceitos científicos, tendo a ciência como única fonte de conhecimentos válidos (COBERN, 2000, p. 2019; COBERN; LOVING, 2001, p. 55). Caso o professor não respeite a diversidade de crenças e queira impor sua visão de mundo, o estudante irá negar todo o conhecimento científico sobre o assunto, como perderá também a confiança e admiração que tem pelo professor.

Baptista (2014, p. 31) chama atenção para o cientificismo, termo utilizado para indicar a posição ideológica que tem a ciência ocidental moderna como a única forma confiável de explicação sobre a natureza, com exclusão dos demais sistemas de conhecimentos. De acordo com Baptista (2014, p, 46), o professor deve estar atento para não interferir nos valores dos estudantes, não impondo ideias cientificas, porque, se assim o fizer, estará assumindo uma postura que qualifica a cultura científica como superior às culturas dos estudantes. Cobern e Loving (2001, p. 50) ressaltam a importância de esclarecer que a ciência não possui respostas para todos os questionamentos levantados e que, portanto, é normal que as pessoas busquem explicações em outros sistemas culturais. 
Seria desejável que os estudantes possam compreender que aprender e expressar os conhecimentos científicos não implica em acreditar neles ou abandonar/negar suas crenças. Uma pessoa pode estudar diversos povos e culturas, compreender suas visões de mundo e valores, divulgá-los social ou cientificamente sem obrigatoriamente adotá-los. Para o professor, o principal interesse deve ser que os alunos aprendam e divulguem o conhecimento científico da forma correta, que tenham uma visão crítica sobre o assunto e que acionem esse conhecimento quando possível em decisões sobre ciência e tecnologia.

Em sua pesquisa, Fourez (2003, pp. 111 - 121) apontou outros obstáculos ao aprendizado do conhecimento científico que também são extremamente relevantes e, por isso, merecem ser citados: 1 - a falta de interesses dos estudantes quanto ao conhecimento científico, 2 - a falta de estímulos governamentais e familiares à formação de pesquisadores, 3 - a falta de credibilidade nas informações científicas devido às informações contraditórias divulgadas pelos meios de comunicação e 4 - as deficiências dos professores relacionadas ao ensino de ciências, aspectos não contemplados na presente pesquisa.

\section{Conclusão}

Por meio da realização da pesquisa constatamos seis obstáculos no aprendizado de um tema que gera conflito entre ciência e religião: a origem da vida. O primeiro se refere à diferença de bagagem de conhecimentos científico e religioso apresentada pelo aluno. O conhecimento religioso é ensinado desde as fases iniciais da vida, enquanto o conhecimento científico é apresentado no período que a criança está nos anos finais do Ensino Fundamental, ou bem mais tarde.

O segundo obstáculo envolve a forma que o conhecimento científico é apresentado nos meios de ensino não formais, como séries, filmes e animações, algumas vezes divulgando informações equivocadas. 
O terceiro obstáculo está relacionado à falta de diferenciação dos significados das palavras teoria e lei, o que faz com que muitos estudantes pensem que as teorias científicas sobre origem da vida e evolução não são confiáveis.

O quarto obstáculo menciona a dificuldade que existe em superar conhecimentos equivocados, mesmo que a informação cientificamente válida seja apresentada, pois com o tempo ela pode ser esquecida e suprida pela ideia anterior. Nesta situação, é indicado que o tema seja revisado em diversos momentos e utilizando diferentes estratégias.

O quinto obstáculo envolve a rejeição das teorias científicas por razões religiosas. No entanto, a crença pode coexistir com o conhecimento científico sem que exista conflito, o que dependerá das orientações que o estudante receberá da escola, da família e da sociedade.

O sexto obstáculo está relacionado à postura do professor, que precisa ter uma visão multicultural da sala de aula. As crenças na ciência e na religião podem estar presentes em um mesmo indivíduo de forma a coexistirem, desde que sejam mobilizadas no contexto adequado. A ciência se preocupa com o mundo natural e como ele funciona; a religião atribui outros sentidos à realidade, lidando com rituais, dimensões emocionais e místicas, o que deve ser esclarecido durante as aulas.

Um tema que envolve conflito entre ciência e religião não impede a aprendizagem, mas requer a compreensão das diferenças entre conhecimento científico e crenças pessoais, bem como esclarecimentos de que não é necessária a realização de uma escolha, pois podemos conhecer uma informação, concordando ou não com ela.

O conhecimento pode proporcionar reflexões para um pensar crítico sobre uma série de questões dos mais variados domínios. A filosofia, a ética, a política, a ciência e a religião podem conviver em um mesmo indivíduo para traçar o melhor rumo para sua vida e, portanto, para a sociedade. Deve-se respeitar a diversidade sociocultural, como também os espaços de 
atuação dos indivíduos, para assim se construir uma sociedade cada vez mais igualitária e justa.

\section{Referências}

ALMEIDA, L. M. W.; FONTANINI, M. L. C. Aprendizagem significativa em atividades de modelagem matemática: uma investigação usando mapas conceituais. Investigações em Ensino de Ciências, v. 15, n. 2, p. 403-425, 2010. Disponível em: <https://www.if.ufrgs.br/cref/ojs/index.php/ienci/article/view/302/197>. Acesso em: 01 fev. 2019.

ALTERS, B. J. Teaching biological evolution in higher education. Methodological, religious and nonreligious issues. Canada: Jonas and Bartlett Publishers, 2004. 261p.

ARAÚJO, C. A. A. A ciência como forma de conhecimento. Rev. Ciência e Cognição, v. 8, p. 127-142, 2006. Disponível em: <pepsic.bvsalud.org/pdf/cc/v8/v8a14.pdf>. Acesso em: 01 fev. 2019.

AUSUBEL, D. P. Adquisición y retención del conocimiento: Uma perspectiva cognitiva. Barcelona: Ed. Paidós Ibérica, 2000. 325p.

Educational Psychology: A cognitive view. New York: Holt, Rinehart and Winston, 1968. 733p.

BAPTISTA, G. C. S. Do cientificismo ao diálogo intercultural na formação do professor e ensino de ciências. Interacções, n. 31, p. 28-53, 2014. Disponível em: $<$ https://revistas.rcaap.pt/interaccoes/article/view/6369/4938>. Acesso em: $01 \mathrm{fev}$. 2019 .

COBERN, W. The nature of science and the role of knowledge and belief. Science \& Education, v. 9, p. 219-246, maio 2000. Disponível em: $<$ https://link.springer.com/article/10.1023/A:1008747309880>. Acesso em: 01 fev. 2019.

COBERN, W.; LOVING, C. C. Defining science in a multicultural world: implications for science education. Science Education, New York, v. 85, n. 1, p. 5067, 2001. Disponível em: $<$ https://www.researchgate.net/publication/240858807_Defining_science_in_a_mult icultural_world_Implications_for_science_education>. Acesso em: 01 fev. 2019.

FOUREZ, G. Crise no ensino de ciências? Investigações em Ensino de Ciências, v. 8, n. $2, \quad$ p. 109-123, 2003. Disponível em: <https://www.if.ufrgs.br/cref/ojs/index.php/ienci/article/view/542/337>. Acesso em: 01 fev. 2019. 
HANLEY, P.: BENNETT. J.; RATCLIFFE, M. The inter-relationship of science and religion: A typology of engagement. International Journal of Education, v. 36, n. 7, p. 1210-1229, 2014. Disponível em: <https://www.tandfonline.com/doi/abs/10.1080/09500693.2013.853897>. Acesso em: 01 fev. 2019.

MARQUES, F. Visões nubladas. Pesquisa FAPESP, Edição 236, p. 40-43, out. 2015. Disponível em: <http://revistapesquisa.fapesp.br/2015/10/14/visoes-nubladas/>. Acesso em: 01 fev. 2019.

MARUYAMA, U.; BRAGA, M.; GUERRA, A. Leis e teorias: identificando aspectos sobre visões de natureza da ciência em estudantes do ensino médio num curso de física experimental. In: VIII ENPEC, 2011. Campinas. Anais... Abrapec, 2011, 8p. Disponível em: <http://www.nutes.ufrj.br/abrapec/viiienpec/resumos/R0257-1.pdf>. Acesso em: 17 jun. 2017.

MELLO, A. C. Evolução biológica: concepções de alunos e reflexões didáticas. 2008. 114 f. Dissertação (Mestrado em Educação em Ciências e Matemática). Faculdade de Física, Pontifícia Universidade Católica do Rio Grande do Sul, Porto Alegre, 2008. Disponível em: <http://repositorio.pucrs.br/dspace/handle/10923/3048>. Acesso em: 01 fev. 2019.

MILLER J. D; SCOTT E. C.; OKAMOTO, S. Public acceptance of evolution. Science, v. 313, p. 765-766, aug. 2006. Disponível em: $<$ https://www.researchgate.net/publication/6885439_Public_Acceptance_of_Evolutio n>. Acesso em: 01 fev. 2019

MOREIRA, M. A. O que é afinal aprendizagem significativa? Qurriculum: Revista de Teoría, Investigación y Práctica Educativa, La Laguna, Espanha, n. 25, p. 29-56, mar. 2012. Disponível em: <http://moreira.if.ufrgs.br/oqueeafinal.pdf>. Acesso em: 01 fev. 2019.

¿Aprendizagem significativa: um conceito subjacente? In: ENCONTRO INTERNACIONAL SOBRE APRENDIZAGEM SIGNIFICATIVA, 1997, Burgos, Espanha. Actas. Burgos: Enas, 1997, 27f. Disponível em: $<$ https://www.if.ufrgs.br/ moreira/apsigsubport.pdf>. Acesso em: 01 fev. 2019.

MORESI, E. Metodologia da Pesquisa. Univ. Católica de Brasília, 2003. 108p. Disponível em: <https://inf.ufes.br/ pdcosta/ensino/2010-2-metodologia-depesquisa/MetodologiaPesquisa-Moresi2003.pdf>. Acesso em: 19 abr. 2019.

MOTA, H. S. Evolução Biológica e Religião: atitudes de jovens estudantes brasileiros. 2013. 272 f. Tese (Doutorado em Educação). Faculdade de Educação, Universidade de São Paulo, São Paulo, 2013. Disponível em: $<$ http://www.teses.usp.br/teses/disponiveis/48/48134/tde-28012014-143821/ptbr.php>. Acesso em: 01 fev. 2019.

NASCIMENTO, N. C. A aprendizagem de um tema que gera conflito entre ciência e crença: Uma investigação com estudantes do ensino médio técnico. 2017. $250 \mathrm{f}$. Tese (Doutorado em Ensino, Filosofia e História das Ciências). Instituto de Física, 
Universidade Federal da Bahia, Salvador, 2017. Disponível em: <https://repositorio.ufba.br/ri/handle/ri/24737>. Acesso em: 01 fev. 2019.

OLIVEIRA, G. S. Evolução biológica e os estudantes brasileiros: conhecimento e aceitação. 2015. 315 f. Tese (Doutorado em Educação) Faculdade de Educação, Universidade de São Paulo, São Paulo, 2015. Disponível em: $<$ https://www.if.ufrgs.br/cref/ojs/index.php/ienci/article/view/48>. Acesso em: 01 fev. 2019.

Aceitação/rejeição da evolução biológica: atitudes de alunos da educação básica. 2009. 162 f. Dissertação (Mestrado em Educação). Faculdade de Educação, Universidade de São Paulo, São Paulo, 2009. Disponível em: $<$ http://www.teses.usp.br/teses/disponiveis/48/48134/tde-26022010-093911/ptbr.php>. Acesso em: 01 fev. 2019.

PORTO, P. R. A.; FALCÃO, E. B. M. Teorias da origem e evolução da vida: dilemas e desafios no ensino médio. Rev. Ensaio, Belo Horizonte, v. 12, n. 3, p.13-30, set./dez. 2010. Disponível em: <http://www.scielo.br/scielo.php?pid=S198321172010000300013\&script=sci_abstract\&tlng=pt>. Acesso em: 01 fev. 2019.

SILVA, H. M.; SILVA, P. R.; SOUZA, A. C. L.; ARAUJO, E. S. N. N. A influência da religiosidade na aceitação do evolucionismo: um estudo em uma amostra da população brasileira. Conexão Ciência, Formiga, v. 8, n. 1, p. 1-19, jan./jun. 2013. Disponível em: $<$ https://www.researchgate.net/publication/321786763_A_influencia_da_religiosida de_na_aceitacao_do_evolucionismo_um_estudo_em_uma_amostra_da_populacao_br asileira>. Acesso em: 01 fev. 2019.

TRIGO, E. D. F. Ciências, um convidado especial na sala de aula de Biologia Estudo exploratório de um encontro cultural entre ciência e religião no Ensino Médio. 2005. 260 f. Dissertação (Mestrado em Tecnologia Educacional para a Saúde do NUTES), Centro de Ciências da Saúde, Universidade Federal do Rio de Janeiro, Rio de Janeiro, 2005. 